\title{
A Patient Charter for Chronic Obstructive Pulmonary Disease
}

John R. Hurst · Tonya Winders $\cdot$ Heinrich Worth $\cdot$ Mohit Bhutani $\cdot$

Kevin Gruffydd-Jones • Daiana Stolz $\cdot$ Mark T. Dransfield

Received: October 13, 2020 / Accepted: November 16, 2020 / Published online: November 27, 2020

(C) The Author(s) 2020

\begin{abstract}
Chronic obstructive pulmonary disease (COPD) has a profound impact on people living with the disease and has a high global economic and social burden. Often, people with COPD are undiagnosed, while those diagnosed are undertreated and undereducated on different aspects
\end{abstract}

J. R. Hurst $(\bowtie)$

UCL Respiratory, University College London, London, UK

e-mail: j.hurst@ucl.ac.uk

T. Winders

Allergy and Asthma Network, Global Allergy and

Airways Patient Platform, Vienna, VA, USA

H. Worth

Vice-Chairman of the German Airways League, Specialists Forum, Furth, Germany

M. Bhutani

Division of Pulmonary Medicine, Department of Medicine, University of Alberta, Edmonton, AB, Canada

K. Gruffydd-Jones

Box Surgery, Box, Corsham, Wiltshire, UK

D. Stolz

Clinic of Respiratory Medicine and Pulmonary Cell Research, University Hospital Basel, Basel,

Switzerland

\section{T. Dransfield}

Division of Pulmonary, Allergy, and Critical Care Medicine, Lung Health Center, The University of Alabama at Birmingham, Birmingham, AL, USA of COPD care. Although there are many published evidence-based treatment guidelines from different expert groups and societies, they are frequently not adhered to, which results in significant gaps in care. In particular, 'flare-ups' (known as exacerbations of COPD), which accelerate disease progression, are often underreported, despite guidelines recommending an escalation of maintenance treatment to prevent subsequent flare-ups. Management of COPD should be proactive to prevent worsening of symptoms and to reduce the risk of future flareups and premature death, rather than a secondary reaction to a worsening health status. Key to this is patient access to accurate diagnosis, effective treatment and specialist care, which can vary widely due to socioeconomic differences, geographical locations and poor guideline implementation. In addition, the stigma associated with COPD can act as a barrier, which can result in people being reluctant to access treatment or clinicians being nihilistic. As global patient advocates, we have co-developed this patient charter to set a standard of care that people living with COPD should expect, raising awareness and understanding of the causes and consequences of COPD as well as the potential to improve patient care. Patients with COPD should be empowered to live the highest quality of life possible with the least number of flare-ups. We set out six principles in line with current COPD guideline recommendations, that should be implemented by 
governments, healthcare providers, policymakers, lung health industry partners and patients/caregivers to drive meaningful change in COPD care.

Keywords: Caregivers; Chronic obstructive pulmonary disease; Patient advocacy; Patient care; Quality of life; Socioeconomic factors; Treatment outcome

\section{Key Summary Points}

Why provide this perspective piece?

Although there are many published evidence-based treatment guidelines for COPD from different expert groups and societies, they are not always adhered to, which results in significant gaps in care.

In particular, 'flare-ups' (known as exacerbations of COPD), which can accelerate disease progression, are often under-reported or untreated, despite guidelines recommending an escalation of treatment to prevent subsequent flare-ups.

\section{What can be learned from this perspective piece?}

Management of COPD should be proactive to prevent worsening of symptoms, frequent flare-ups and premature death, rather than a secondary reaction to a worsening health status.

Key to this is patient access to effective diagnosis, treatment and specialist care, which can vary widely due to socioeconomic differences, geographical locations and poor guideline implementation.

As global patient advocates, we have developed this patient charter to set a standard of care quality that patients living with COPD should expect, to raise awareness and to improve outcomes.

\section{DIGITAL FEATURES}

This article is published with digital features, including a summary slide, to facilitate understanding of the article. To view digital features for this article go to https://doi.org/10.6084/ m9.figshare.13241684.

\section{INTRODUCTION}

Chronic obstructive pulmonary disease (COPD) is a progressive lung condition characterised by persistent respiratory symptoms (shortness of breath, chronic cough and sputum production) and impaired lung function. Patients also experience 'flare-ups' (known as exacerbations of COPD), which are a period of acute worsening of symptoms that can accelerate disease progression, markedly worsen quality of life, and, when severe, lead to hospitalisation and even death. The severity of symptoms, lung function impairment, impact on daily life and frequency of flare-ups vary considerably between patients and are driven by numerous factors $[1,2]$. In addition, it has been estimated that $70 \%$ of cases of COPD worldwide may be underdiagnosed [3], while COPD management often does not follow treatment guidelines [4-7].

COPD is estimated to affect 384 million people worldwide [8] and is the third leading cause of global death [9], impacting high-, middle- and low-income countries (Fig. 1) [10]. In addition, the burden of COPD is growing: In 2015, 3.2 million people died from COPD worldwide, an increase of nearly $12 \%$ compared with 1990 [11]. COPD therefore places a significant burden on the global economy, of which direct medical costs account for $61-86 \%$ $[2,12,13]$. Indirect costs, such as lost productivity, are significant in COPD, as many people suffer with the disease for years, often developing further chronic conditions that can add to the suffering and result in early death [2].

A number of guidelines and strategy documents that define best practice in COPD care based on the latest evidence (including those from the Global Initiative for Chronic Obstructive Lung Disease (GOLD) [2], the 
American Thoracic Society [14], the European Respiratory Society [15] and the Canadian Thoracic Society [16]) are available. However, further enhancements in the diagnosis and treatment of COPD are required [17], along with significant improvements in guideline implementation.

We, as clinicians and representatives of patient support groups, have developed a COPD patient charter comprising six principles of quality care that patients should expect to receive, wherever they live. The purpose of this charter is to mobilise governments, healthcare providers, policymakers, lung health industry partners and patients/caregivers to address the unmet need and burden in COPD, ultimately working together to deliver meaningful improvements in care, both now and in the future.

This article does not contain any studies with human participants or animals performed by any of the authors.

\section{DEVELOPING THE PATIENT CHARTER}

Representatives of three national patient organisations along with seven clinicians discussed the value of establishing a patient charter as a potential starting point for discussions on how to reform care for patients with COPD. This patient charter was subsequently initiated by AstraZeneca and aims to set a standard for what people living with COPD should expect from their ongoing care. These expectations are in line with the current best practice understanding from existing COPD guidelines and aim to offer a consensus on global standards of COPD care while driving timely, evidence-based treatment to maintain health status, minimise symptoms and prevent flare-ups.

The three patient organisations involved are all members of the Global Allergy and Asthma Patient Platform and are dedicated to COPD awareness, education and advocacy; together, their memberships cover more than 50 million patients with COPD across the USA, the United Kingdom and Spain. The principal concepts

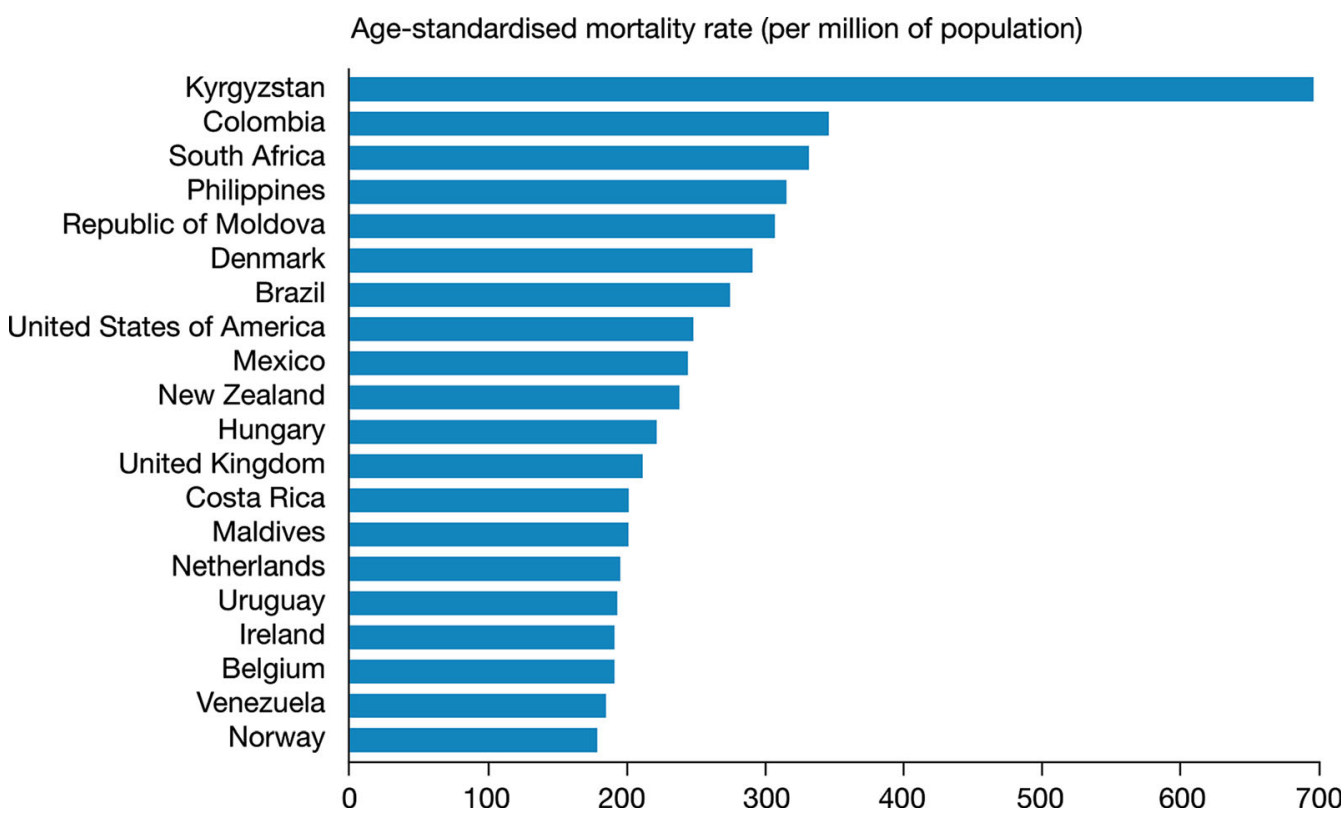

Fig. 1 Top 20 countries with the highest number of COPD deaths per million per year, 2001-2010; COPD chronic obstructive pulmonary disease (Modified with permission from British Lung Foundation, number of
COPD deaths per million per year by country, 2001-10 figure. Available from https://statistics.blf.org.uk/copd, accessed 11 November 2020) 
were developed by a working group of 20 clinicians and patient representatives, and were debated and refined during a discussion held on 15 May 2020, organised and funded by AstraZeneca.

\section{Principle 1: I Deserve Timely Access for the Diagnosis and Assessment of My COPD}

Symptoms in the early stages of COPD may be absent or mild and are not well recognised by patients, who often assume their symptoms are a result of ageing or of exposure to cigarette smoke or other irritants [18]. As such, COPD is often diagnosed at a more advanced stage, when it is associated with more severe symptoms, increased risk of flare-ups and an increase in other chronic conditions and costs [19]. In addition, although individual rates of lung function decline vary widely $[1,20]$, a more rapid decline occurs in those with mild and moderate COPD than with severe/very severe COPD [20-22]. While almost $90 \%$ of cases of COPD may be undiagnosed worldwide [23], people who were defined as having COPD according to their impaired lung function, but were not diagnosed by a clinician, were shown to use healthcare services for their symptoms to the same extent as diagnosed people but without being properly managed and treated [24]. Consequently, undiagnosed COPD places a significant burden on people and the healthcare system.

COPD symptoms are known to have daily, weekly and seasonal variability [25]; people have reported that the morning is the worst time of day for symptoms of COPD, with cough and sputum production being most troublesome $[26,27]$. In addition, night-time symptoms and sleep disturbance are common, yet under-recognised, and can lead to long-term changes in lung function, frequency of flareups, risk of heart disease, mental function, depression, quality of life and death [28, 29]. Therefore, in order for people to better recognise the symptoms of COPD, it is vital to increase awareness of the types and timings of symptoms that may occur.
Currently, a diagnosis of COPD can only be confirmed using spirometry, a physiological test to assess the presence of poorly-reversible airflow limitation, which should be performed and interpreted by trained individuals [2]. However, it is estimated that only one-third of people newly diagnosed with COPD have spirometry performed [30]. In addition, not only are there other causes of airflow limitation but people without airflow limitation can have smokingrelated lung disease (such as emphysema), may be at risk of flare-ups [31] and may benefit from COPD therapies. Aside from stopping smoking, there are no therapies definitively proven to affect the rate of change in lung function in people with COPD [32], but it is possible to impact symptoms and quality of life and to prevent flare-ups and early death. As such, spirometry alone is not sufficient to inform treatment decisions and should be used alongside other tools, including diaries, that measure and record symptoms and flare-ups, including the modified Medical Research Council questionnaire and COPD assessment test [2]. Patients and healthcare professionals should have access to, and use, the tools required to support them to recognise the initial symptoms of COPD, and have access to the right resources to make an informed and accurate diagnosis.

\section{Principle 2: I Deserve to Understand What Having COPD Means for Me and How the Disease May Progress}

COPD is a highly variable disease, which can be clinically categorised based on symptom severity and history of flare-ups [2]. However, symptoms may change or worsen over time and can lead to more frequent and more severe flareups. People with COPD can also have other diseases such as heart disease, which further contribute to reduced quality of life and worse disease course [33, 34]. These factors should drive a change in how the condition is managed through both pharmacological (i.e. medication) and non-pharmacological means (e.g. exercise, education and stopping smoking).

With increasing demand for COPD services, it is important for patients to become active 
participants in their own care. Self-management interventions in people with COPD are associated with improved health-related quality of life, a reduction in hospital admissions and improvement in symptoms [35]. At an individual patient level, this is not just understanding about disease progression, but a broader concept regarding what having COPD means, understanding their current disease state, the expectations of worsening disease and what that would mean for day-to-day life. It is likely that greater understanding of the consequences of the disease would improve patient engagement with their treatment regimen, and encourage them to raise their expectations about how their life could and should be, with access to the right tools and the right treatment at their disposal. Patients should receive personalised education and training about their COPD, and how it interacts with any other diseases that they may have, to enable them to actively participate in their own care, learn to detect and react to changes in symptoms according to their personalised action plans and report changes to their healthcare professional to prevent further disease progression. To enhance patient engagement, this education could be delivered not only by healthcare providers but also through patient support groups/societies, online resources and the provision of the latest clinical research in the form of plain language summaries.

\section{Principle 3: I Deserve Access to the Best Available Evidence-Based, Personalised Treatment, to Ensure I can Live as Well and as Long as Possible}

Goals for the treatment of COPD are based on reducing symptoms and the risk of future flareups, prevent lung function decline and premature death (Fig. 2) [2]. Many therapies have been shown to be beneficial across these goals, including suggestions of reduced mortality [36-39]. However, many gaps exist in both the non-pharmacological and pharmacological treatment of COPD, with access to smoking cessation support, vaccinations and pulmonary rehabilitation often difficult to obtain [40].
Over two-thirds of people diagnosed with COPD are not prescribed maintenance inhaled therapy [41] and, of those receiving treatment, up to three-quarters of people who experience two or more flare-ups continue to be undertreated according to GOLD recommendations [42]. Conversely, pharmacological overtreatment has been found in approximately onethird of people, with non-pharmacological treatment used too rarely [6].

Undertreatment and overtreatment of COPD can happen for several reasons. Lack of clinician education can contribute to treatment guidelines not being followed and/or poor knowledge of new treatments. Access to specialist care is vital in this respect. For example, patient access to care in the USA varies widely, and healthcare systems struggle to meet their goals for improving COPD burden [43]. In addition, it is essential that people are appropriately diagnosed and that their treatment regimen is reviewed regularly and escalated quickly, if needed. Thus, people with COPD should request an evidence-based and personalised management plan with the treating clinician at both the initial diagnosis and follow-up, to enable a more proactive, timely prevention of disease progression, rather than reacting to a worsening of health status.

GOLD recommends that the management of COPD should include five steps: diagnosis, initial assessment, initial management, review and adjustment (Fig. 3) [2]. Diagnosis is based on symptoms, risk factors and measurement of

\section{Goals for the treatment of stable COPD}

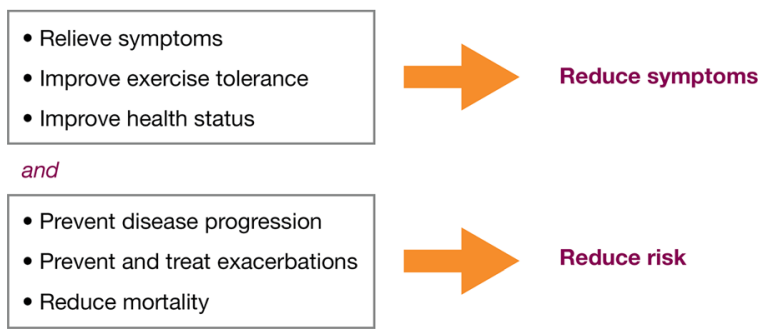

Fig. 2 Goals for the treatment of COPD; COPD chronic obstructive pulmonary disease (Reproduced with permission from Global Initiative for Chronic Obstructive Lung Disease 2020 Report; Table 4.1. Available from https:// goldcopd.org/gold-reports/, accessed 11 November 2020) 
airflow limitation. This is followed by the initial assessment, which delves further into the specific details of the disease, such as history of flare-ups, smoking status and other illnesses. The initial management involves steps including encouraging stopping smoking, lifestyle modifications and non-pharmacological and pharmacological treatment, among others. This is followed by regular and repeated review of patients' disease and health status, followed by adjustment of both pharmacological and nonpharmacological treatment, as required [2]. It is this proactive, regular review and adjustment of treatment that is key to effective management of the disease and ensures that each individual can maximise their potential to live as normal a life as is possible.

\section{Principle 4: I Deserve an Urgent Review} of My Current Management Plan If I Experience a Flare-Up, to Prevent Further Flare-Ups and Disease Progression

Although many people with COPD experience flare-ups, over half of flare-ups go unreported [44]. Hospitalisations resulting from severe flare-ups account for approximately two-thirds of all healthcare costs associated with COPD [45], and frequent moderate (community-treated) flare-ups, or one severe (hospitalised) flareup, significantly increase the risk of death [46].

\section{Management of COPD}

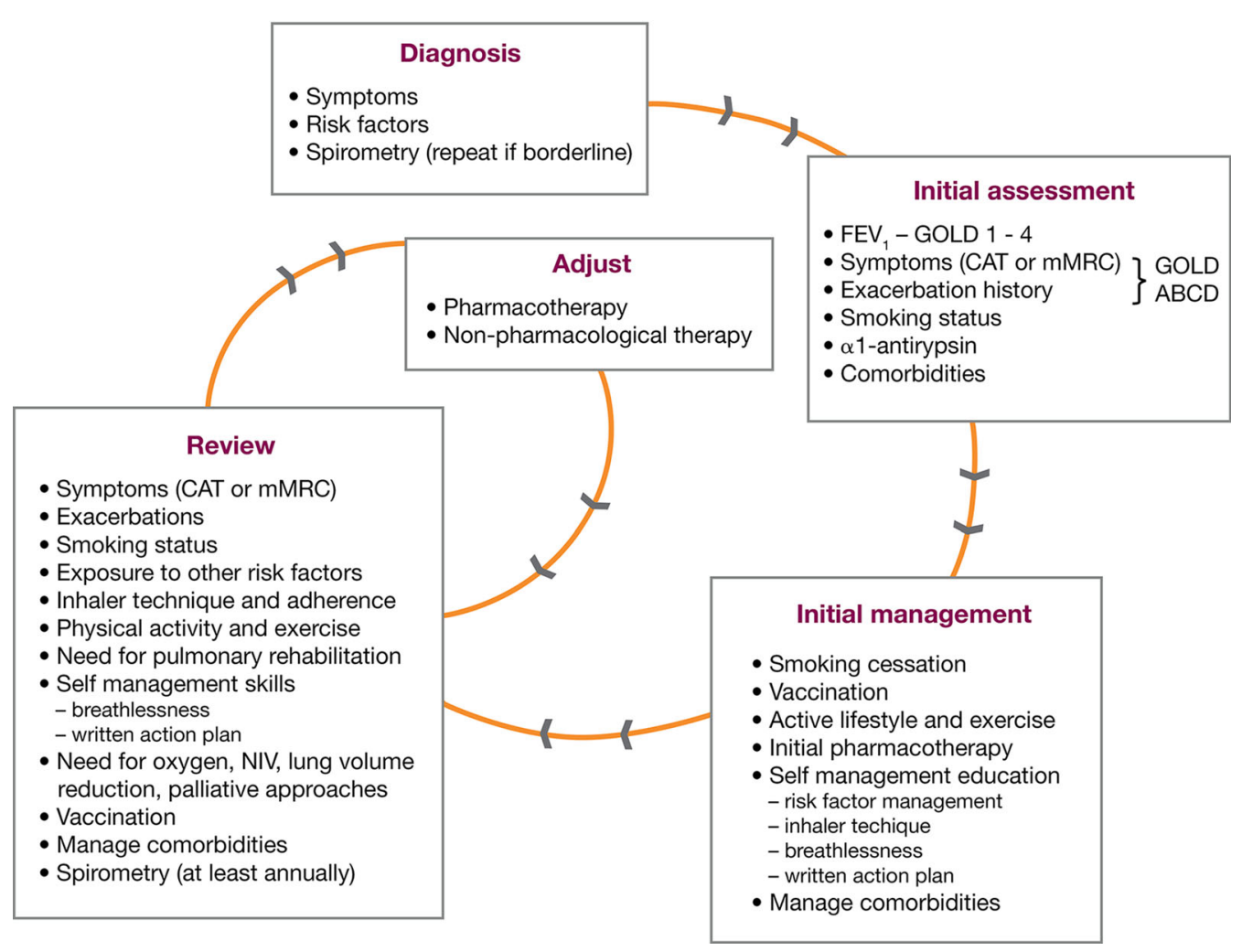

Fig. 3 Management of COPD; CAT COPD assessment test, $C O P D$ chronic obstructive pulmonary disease, $F E V_{1}$ forced expiratory volume in $1 \mathrm{~s}$, GOLD Global Initiative for Chronic Obstructive Lung Disease, $m M R C$ modified Medical Research Council dyspnoea score, NIV noninvasive ventilation (Reproduced with permission from
Global Initiative for Chronic Obstructive Lung Disease 2020 Report; Fig. 4.1. Available from https://goldcopd. org/gold-reports/, accessed 11 November 2020) 
In addition to this, flare-ups are associated with an increased risk of complications, such as heart attacks and strokes [47]. Flare-ups also appear to have a significant impact on mental and emotional well-being and this may be underestimated by clinicians [48]. Thus, flare-ups have a detrimental impact on both patients and society.

Despite this, medical review after a flare-up is suboptimal. Studies have estimated that only one-quarter of people receive adequate treatment to prevent or reduce symptoms after an flare-up [49] and that over half of flare-ups go unreported [44]. Government policymakers and healthcare professionals should appreciate the significant burden associated with COPD and ensure that flare-ups trigger an immediate review of the chronic treatment and disease management. A shift is needed toward a proactive, evidence-based approach to treatment to maintain health status, minimise symptoms and prevent future flare-ups, as opposed to waiting for disease deterioration before review.

\section{Principle 5: I Deserve Access to Specialist Care When Needed (Whether Provided in Hospital or in the Community) to Manage My COPD, Irrespective of Where I Live}

Specialist care refers to care provided by a healthcare professional who has the expert skills and understanding of COPD required to provide appropriate care. Staffing levels and the availability of a specialist respiratory review is linked to reduced risk of death and quality of service in COPD $[50,51]$. In one study, people who received specialist review within $24 \mathrm{~h}$ of admission to hospital for a severe flare-up were $14 \%$ less likely to die as an inpatient compared with those who did not receive specialist review [52]. Similarly, barriers exist in access to outpatient specialist COPD services and pulmonary rehabilitation. This is mainly attributed to limited resources and underfunding, particularly within rural areas [53], with one study estimating that only $35 \%$ of adults in rural areas of the USA had access to specialist care within 10 miles
$(16 \mathrm{~km})$, and residents of many counties in the Midwest had no access to a specialist care within 50 miles $(80 \mathrm{~km})$ [54]. The development of a proactive, planned-care orientation to empower patients and families to collaborate actively with the healthcare team may improve this situation [55].

With the increasing availability of smartphones and other digital technologies, including remote consultations, COPD should become a benchmark of how such technologies can improve current services and enable the provision of tailored, specialist care, regardless of where a person lives. A systematic review and meta-analysis of the effect of smartphone interventions on people with COPD found an $80 \%$ reduction in the odds of experiencing a flare-up in people using smartphone intervention compared with usual care [56]. Although the patient numbers involved were small and there was variability between studies, these findings suggest a potential for smartphone interventions to reduce the frequency of COPD flare-ups; thus, further investigation is warranted. However, as many people with COPD may not have access to such technology, it is vital that its use does not exaggerate health inequalities.

\section{Principle 6: I Deserve to Live with COPD Freely While Maximising Quality of Life Without Stigma or Guilt}

Worldwide, the most common risk factor for COPD is tobacco smoking [2] and, as a result, there is a stigma that it is largely self-inflicted condition of the older population. Due to this stigma, many people experience self-blame, guilt and shame [57]. People with COPD also describe feeling stigmatised by healthcare professionals in some cases, which can lead to a reluctance to access treatment [58]. By way of comparison, although people with lung cancer experienced similar self-blame and guilt, they did not feel stigmatised by healthcare professionals and did not describe themselves as being undeserving of treatment [58].

It is becoming increasingly clear that smoking is only one of a number of risk factors linked 
with COPD, others include indoor (household) and outdoor air pollution, occupational exposure to dust and gases, burning of solid fuels, socioeconomic status and poverty, genetic predispositions, abnormal lung development and accelerated ageing [2, 59-63]. Healthcare professionals, patients and the general public should therefore be educated about the numerous risk factors associated with COPD in order to reduce the associated stigma of the condition, ensuring that people are not discouraged from seeking help.

\section{DISCUSSION}

The global burden of COPD on patients and society is substantial. Despite this, standards of care and appropriate funding can vary widely, and many people do not have adequate access to accurate timely diagnosis and optimal treatment and management programmes. There is a need to raise the levels of patient education and expectations of diagnosis, treatment and the opportunities to maximise quality of life, rather than people accepting their current disease and symptom status as something they have to live with.

The current approach to COPD management of responding to treatment failure is inadequate. Through empowering patients and families to collaborate actively with the healthcare team, COPD management should be transformed into a planned-care approach of pro-active review and adjustment [55]. This may need to include redesigning healthcare delivery systems to provide same-day primary care appointments, common clinical information systems accessible to multiple users, decision support procedures for clinicians and remote specialist consultations. Furthermore, patient activation and education, including self-management skills, will enable people to take care of themselves in between healthcare visits within the community in which they live [64, 65]. Brought together, this might improve efficiencies for both patients and the healthcare system and make the treatment and management of COPD more cost effective.

To implement these principles, we recommend the continual and regular review of each individual's treatment regimen and following a flare-up, as indicated in the GOLD guidelines [2]. Flare-ups of COPD are common, but adequate treatment is only received by a minority of people. It is becoming increasingly clear that even one flare-up can have a significant impact on disease burden, long-term outcomes and the likelihood of future flare-ups. As flare-ups

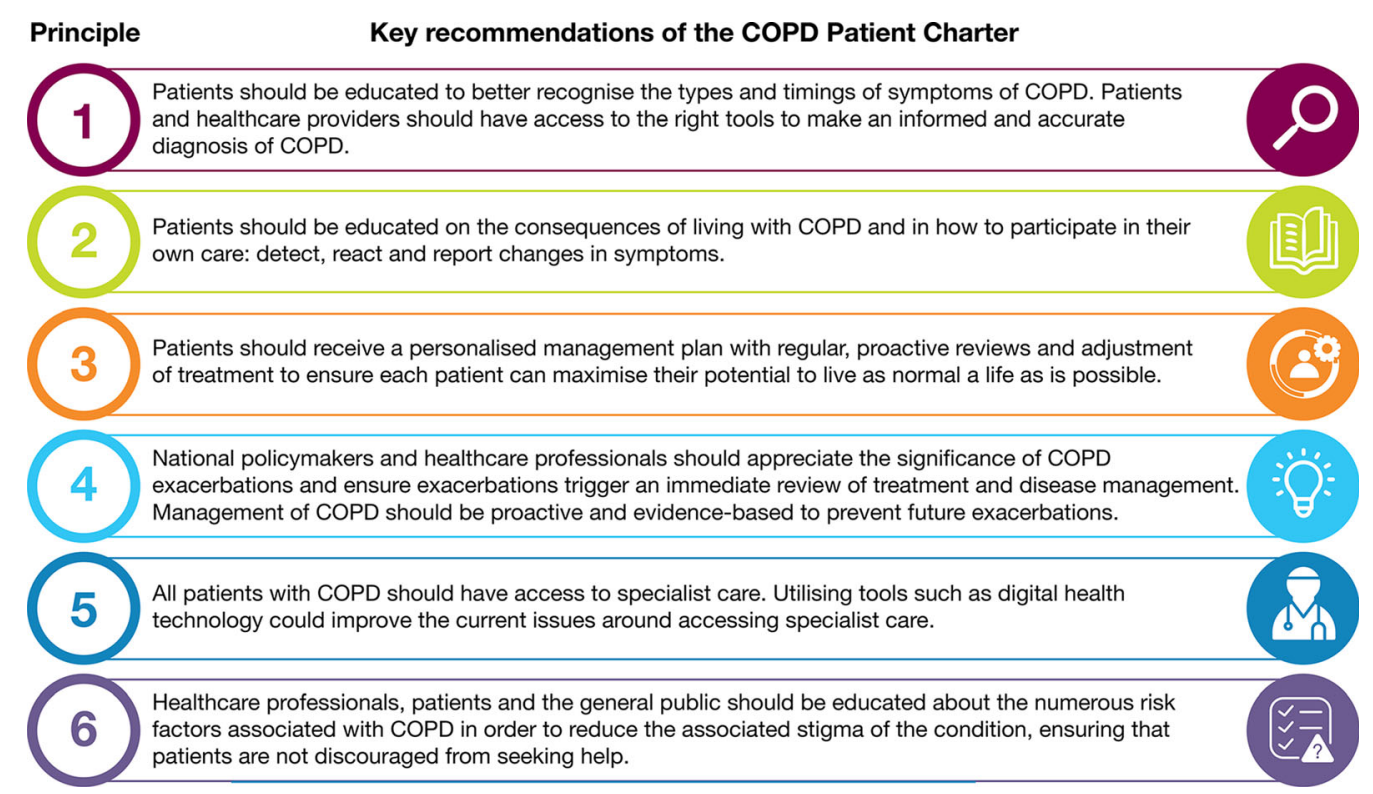

Fig. 4 Key recommendations of the COPD patient charter; COPD chronic obstructive pulmonary disease 
generally occur outside of the regular review cycle, treatment options should be reviewed immediately following a flare-up and escalated as necessary and, in the event of a severe flareup that results in hospitalisation, patients should not be released without a written action plan, agreed by both the patient and the treating clinician. Treatment should be further reviewed to ensure treatment optimisation with the risk of further flare-ups being reduced following any treatment escalation. The key recommendations of our COPD patient charter are outlined in Fig. 4.

\section{CONCLUSION}

As global patient advocates, we believe it is essential to raise the level of awareness and understanding among patients, caregivers, healthcare professionals, policymakers and the public about the impact of COPD and opportunities to reform and improve patient care. The principles we have set out in this COPD patient charter are the core elements of quality care that people with COPD should expect to receive. We urge policymakers and stakeholders to use these principles to build consensus on the care of patients with COPD.

\section{ACKNOWLEDGEMENTS}

The authors wish to thank all members of the patient support groups along with the clinicians and patient representatives involved in the development of this Patient Charter, namely Dr Mohit Bhutani, Professor Jaime Correia de Sousa, Dr Mark Dransfield, Lilliya Gentet, Dr Kevin Gruffydd-Jones, Professor MeiLan Han, Nicole Hass, Professor John Hurst, Dr Fernando Martinez, Dr Marc Miravitlles, Susanna Palkonen, Dr Rudi Peche, Henry Roberts, Professor Nicolas Roche, Debbie Roots, Professor Daiana Stolz, Jamie Sullivan, Dr Hendrik Watz, Tonya Winders and Dr Heinrich Worth.
Funding. This work and the journal's Rapid Service and Open Access Fee were supported by AstraZeneca.

Medical Writing and Editorial Assistance. Medical writing support, under the direction of the authors, was provided by Richard Knight, PhD, of CMC Connect, McCann Health Medical Communications and was funded by AstraZeneca, Gaithersburg, USA in accordance with Good Publication Practice (GPP3) guidelines [66].

Authorship. All named authors meet the International Committee of Medical Journal Editors (ICMJE) criteria for authorship for this article, take responsibility for the integrity of the work as a whole, and have given their approval for this version to be published.

Disclosures. None of the authors were compensated for the development of this manuscript. John R Hurst has received support to attend meetings and payment (personal and to his employer) for educational and advisory work from pharmaceutical companies including AstraZeneca, Boehringer Ingelheim, GSK, Novartis and Pfizer that make medicines to treat COPD. Tonya Winders is the President of Global Allergy and Airways Patient Platform (GAAPP), and under a compensatory agreement serves in an advisor capacity only to AstraZeneca in asthma and COPD to support unbranded disease awareness and education. Heinrich Worth has received speaking and consulting fees from AstraZeneca, Berlin Chemie, Chiesi, GlaxoSmithKline, Klosterfrau, MSD, Novartis and Omron. Mohit Bhutani has received speaking and consulting fees from AstraZeneca, Boehringer Ingelheim, GlaxoSmithKline, Novartis, Pfizer, Sanofi Genzyme, Grifols and grants from AstraZeneca, Boehringer Ingelheim, Canadian Institutes of Health Research, GlaxoSmithKline and Novartis outside of this work. Kevin Gruffydd-Jones has recevied speaker fees and honoraria for consultancy work from Boehringer Ingelheim, GlaxoSmithkline, AstraZeneca, Napp, TEVA, Chiesi, Nutricia and Novartis. Daiana Stolz has received speaking fees from Novartis, AstraZeneca, 
GlaxoSmithKline, Roche, Zambon, Pfizer and Schwabe Pharma. Her institution has received unrestricted research grants from AstraZeneca, Curetis, Boston Scientific, Circassia Pharmaceuticals and Swiss National Foundation. Mark $\mathrm{T}$ Dransfield has received grant support from the American Lung Association, Department of Defense and NIH; personal fees from AstraZeneca, Boehringer Ingelheim, PneumRx/BTG, Quark Pharmaceuticals, TEVA and GSK; and contracted clinical trial support from Boehringer Ingelheim, AstraZeneca, Yungjin, PneumRx/ BTG, Pulmonx, Boston Scientific, Gala, Nuvaira and GSK.

Compliance with Ethics Guidelines. This article does not contain any studies with human participants or animals performed by any of the authors.

Open Access. This article is licensed under a Creative Commons Attribution-NonCommercial 4.0 International License, which permits any non-commercial use, sharing, adaptation, distribution and reproduction in any medium or format, as long as you give appropriate credit to the original author(s) and the source, provide a link to the Creative Commons licence, and indicate if changes were made. The images or other third party material in this article are included in the article's Creative Commons licence, unless indicated otherwise in a credit line to the material. If material is not included in the article's Creative Commons licence and your intended use is not permitted by statutory regulation or exceeds the permitted use, you will need to obtain permission directly from the copyright holder. To view a copy of this licence, visit http://creativecommons.org/licenses/by$\mathrm{nc} / 4.0 /$.

\section{REFERENCES}

1. Lange P, Celli B, Agustí A, et al. Lung-function trajectories leading to chronic obstructive pulmonary disease. N Engl J Med. 2015;373:111-22.

2. Global Initiative for Chronic Obstructive Lung Disease. Global strategy for the diagnosis, management, and prevention of chronic obstructive pulmonary disease. 2020 Report. 2020. https:// goldcopd.org/wp-content/uploads/2019/11/GOLD2020-REPORT-ver1.0wms.pdf. Accessed 11 Nov 2020.

3. Diab N, Gershon AS, Sin DD, et al. Underdiagnosis and overdiagnosis of chronic obstructive pulmonary disease. Am J Respir Crit Care Med. 2018;198:1130-9.

4. Price D, West D, Brusselle G, et al. Management of COPD in the UK primary-care setting: an analysis of real-life prescribing patterns. Int J Chronic Obstruct Pulm Dis. 2014;9:889-904.

5. Albitar HAH, Iyer VN. Adherence to Global Initiative for Chronic Obstructive Lung Disease guidelines in the real world: current understanding, barriers, and solutions. Curr Opin Pulm Med. 2020;26:149-54.

6. Worth H, Buhl R, Criee CP, Kardos P, Mailander C, Vogelmeier C. The 'real-life' COPD patient in Germany: the DACCORD study. Respir Med. 2016;111: 64-71.

7. Tabyshova A. Gaps in COPD guidelines of low- and middle-income countries: a systematic scoping review. Chest. 2020. (Published Online 7 October).

8. Adeloye D, Chua S, Lee $\mathrm{C}$, et al. Global and regional estimates of COPD prevalence: systematic review and meta-analysis. J Glob Health. 2015;5:020415.

9. World Health Organization. The top 10 causes of death. 2018. https://www.who.int/news-room/factsheets/detail/the-top-10-causes-of-death. Accessed 22 July 2020.

10. British Lung Foundation. Chronic obstructive pulmonary disease (COPD) statistics. 2012. https:// statistics.blf.org.uk/copd. Accessed 11 Nov 2020.

11. GBD 2015 Chronic Respiratory Disease Collaborators. Global, regional, and national deaths, prevalence, disability-adjusted life years, and years lived with disability for chronic obstructive pulmonary disease and asthma, 1990-2015: a systematic analysis for the Global Burden of Disease Study 2015. Lancet Respir Med. 2017;5:691-706.

12. Chen X, Wang N, Chen Y, Xiao T, Fu C, Xu B. Costs of chronic obstructive pulmonary disease in urban areas of China: a cross-sectional study in four cities. Int J Chronic Obstruct Pulm Dis. 2016;11:2625-32.

13. Nishimura S, Zaher C. Cost impact of COPD in Japan: opportunities and challenges? Respirology. 2004;9:466-73. 
14. Nici L, Mammen MJ, Charbek E, et al. Pharmacologic management of chronic obstructive pulmonary disease. An official American Thoracic Society clinical practice guideline. Am J Respir Crit Care Med. 2020;201:e56-69.

15. Wedzicha JA, ERS Co-Chair, Miravitlles M, Hurst JR, et al. Management of COPD exacerbations: a European Respiratory Society/American Thoracic Society guideline. Eur Respir J. 2017;49:1600791.

16. Bourbeau J, Bhutani M, Hernandez P, et al. Canadian Thoracic Society Clinical Practice Guideline on pharmacotherapy in patients with COPD - 2019 update of evidence. Can J Respir Crit Care Sleep Med. 2019;3:210-32.

17. Miravitlles M, Vogelmeier C, Roche N, et al. A review of national guidelines for management of COPD in Europe. Eur Respir J. 2016;47:625-37.

18. Larsson K, Janson C, Ställberg B, et al. Impact of COPD diagnosis timing on clinical and economic outcomes: the ARCTIC observational cohort study. Int J Chronic Obstruct Pulm Dis. 2019;14: 995-1008.

19. van der Molen T, Miravitlles M, Kocks JW. COPD management: role of symptom assessment in routine clinical practice. Int J Chronic Obstruct Pulm Dis. 2013;8:461-71.

20. Vestbo J, Edwards LD, Scanlon PD, et al. Changes in forced expiratory volume in 1 second over time in COPD. N Engl J Med. 2011;365:1184-92.

21. Jenkins CR, Jones PW, Calverley PMA, et al. Efficacy of salmeterol/fluticasone propionate by GOLD stage of chronic obstructive pulmonary disease: analysis from the randomised, placebo-controlled TORCH study. Respir Res. 2009;10:59.

22. Dransfield MT, Kunisaki KM, Strand MJ, et al. Acute exacerbations and lung function loss in smokers with and without chronic obstructive pulmonary disease. Am J Respir Crit Care Med. 2017;195: 324-30.

23. Gershon AS, Hwee J, Chapman KR, et al. Factors associated with undiagnosed and overdiagnosed COPD. Eur Respir J. 2016;48:561-4.

24. Labonté LE, Tan WC, Li PZ, et al. Undiagnosed chronic obstructive pulmonary disease contributes to the burden of health care use. Data from the CanCOLD study. Am J Respir Crit Care Med. 2016;194:285-98.

25. Lopez-Campos JL, Calero C, Quintana-Gallego E. Symptom variability in COPD: a narrative review. Int J Chronic Obstruct Pulm Dis. 2013;8:231-8.
26. Partridge MR, Karlsson N, Small IR. Patient insight into the impact of chronic obstructive pulmonary disease in the morning: an internet survey. Curr Med Res Opin. 2009;25:2043-8.

27. Roche N, Chavannes NH, Miravitlles M. COPD symptoms in the morning: impact, evaluation and management. Respir Res. 2013;14:112.

28. Agusti A, Hedner J, Marin JM, Barbé F, Cazzola M, Rennard S. Night-time symptoms: a forgotten dimension of COPD. Eur Respir Rev. 2011;20: 183-94.

29. Lange P, Marott JL, Vestbo J, Nordestgaard BG. Prevalence of night-time dyspnoea in COPD and its implications for prognosis. Eur Respir J. 2014;43: 1590-8.

30. Han MK, Kim MG, Mardon R, et al. Spirometry utilization for COPD: how do we measure up? Chest. 2007;132:403-9.

31. Woodruff PG, Barr RG, Bleecker E, et al. Clinical significance of symptoms in smokers with preserved pulmonary function. $\mathrm{N}$ Engl $\mathrm{J}$ Med. 2016;374:1811-21.

32. Mosenifar Z. Chronic obstructive pulmonary disease (COPD) treatment \& management. 2019. https://emedicine.medscape.com/article/297664treatment. Accessed 22 July 2020.

33. Westerik JAM, Metting EI, van Boven JFM, Tiersma W, Kocks JWH, Schermer TR. Associations between chronic comorbidity and exacerbation risk in primary care patients with COPD. Respir Res. 2017;18: 31.

34. Negewo NA, McDonald VM, Gibson PG. Comorbidity in chronic obstructive pulmonary disease. Respir Investig. 2015;53:249-58.

35. Zwerink M, Brusse-Keizer M, van der Valk PD, et al. Self management for patients with chronic obstructive pulmonary disease. Cochrane Database Syst Rev. 2014;CD002990.

36. Celli B, Decramer M, Kesten S, et al. Mortality in the 4-year trial of tiotropium (UPLIFT) in patients with chronic obstructive pulmonary disease. Am J Respir Crit Care Med. 2009;180:948-55.

37. Lipson DA, Crim C, Criner GJ, et al. Reduction in all-cause mortality with fluticasone furoate/umeclidinium/vilanterol in COPD patients. Am J Respir Crit Care Med. 2020;201:1508-16.

38. Scuri M, Fabbri LM, Singh D, et al. Reduction in fatal events with ICS-containing medications: results of safety pooled analysis from the TRILOGY, 
TRINITY and TRIBUTE studies [abstract]. Am J Respir Crit Care Med. 2018;197:A7725.

39. Rabe KF, Martinez FJ, Ferguson GT, et al. Triple inhaled therapy at two glucocorticoid doses in moderate-to-very-severe COPD. $\mathrm{N}$ Engl J Med. 2020;383:35-48.

40. Johnston KN, Young M, Grimmer-Somers KA, Antic $\mathrm{R}$, Frith PA. Why are some evidence-based care recommendations in chronic obstructive pulmonary disease better implemented than others? Perspectives of medical practitioners. Int J Chronic Obstruct Pulm Dis. 2011;6:659-67.

41. Make B, Dutro MP, Paulose-Ram R, Marton JP, Mapel DW. Undertreatment of COPD: a retrospective analysis of US managed care and medicare patients. Int J Chronic Obstruct Pulm Dis. 2012;7: $1-9$.

42. Halpin DMG, de Jong HJI, Carter V, Skinner D, Price D. Distribution, temporal stability and appropriateness of therapy of patients with COPD in the UK in relation to GOLD 2019. EClinMed. 2019;14: 32-41.

43. Han MK, Martinez $\mathrm{CH}, \mathrm{Au} \mathrm{DH}$, et al. Meeting the challenge of COPD care delivery in the USA: a multiprovider perspective. Lancet Respir Med. 2016;4:473-526.

44. Xu W, Collet J-P, Shapiro S, et al. Negative impacts of unreported COPD exacerbations on health-related quality of life at 1 year. Eur Respir J. 2010;35: 1022-30.

45. Halpin DM, Miravitlles M, Metzdorf N, Celli B. Impact and prevention of severe exacerbations of COPD: a review of the evidence. Int J Chronic Obstruct Pulm Dis. 2017;12:2891-908.

46. Rothnie KJ, Müllerová H, Smeeth L, Quint JK. Natural history of chronic obstructive pulmonary disease exacerbations in a general practice-based population with chronic obstructive pulmonary disease. Am J Respir Crit Care Med. 2018;198: 464-71.

47. Donaldson GC, Hurst JR, Smith CJ, Hubbard RB, Wedzicha JA. Increased risk of myocardial infarction and stroke following exacerbation of COPD. Chest. 2010;137:1091-7.

48. Kessler R, Ståhl E, Vogelmeier C, et al. Patient understanding, detection, and experience of COPD exacerbations: an observational, interview-based study. Chest. 2006;130:133-42.

49. Dalal AA, Shah MB, D'Souza AO, Lunacsek OE, Nagar SP, Crater GD. Observational study of the outcomes and costs of initiating maintenance therapies in patients with moderate exacerbations of COPD. Respir Res. 2012;13:41.

50. Hartl S, Lopez-Campos JL, Pozo-Rodriguez F, et al. Risk of death and readmission of hospital-admitted COPD exacerbations: European COPD audit. Eur Respir J. 2016;47:113-21.

51. Lane ND, Brewin K, Hartley TM, et al. Specialist emergency care and COPD outcomes. BMJ Open Respir Res. 2018;5:e000334.

52. Royal College of Physicians. National Asthma and COPD Audit Programme (NACAP): COPD clinical audit 2017/18. 2019. https://www.rcplondon.ac.uk/ projects/outputs/national-asthma-and-copd-auditprogramme-nacap-copd-clinical-audit-201718. Accessed 22 July 2020.

53. European Federation of Allergy and Airways Diseases Patients' Associations (EFA). Minimum standards of care for COPD patients in Europe. 2014. https://www.efanet.org/images/2014/10/EFA-BookMinimum-Standards-of-Care-for-COPD-Patients-inEurope_ENGLISH.pdf. Accessed 22 July 2020.

54. Croft JB, Lu H, Zhang X, Holt JB. Geographic accessibility of pulmonologists for adults with COPD: United States, 2013. Chest. 2016;150: 544-53.

55. Fromer L. Implementing chronic care for COPD: planned visits, care coordination, and patient empowerment for improved outcomes. Int $\mathrm{J}$ Chronic Obstruct Pulm Dis. 2011;6:605-14.

56. Alwashmi M, Hawboldt J, Davis E, Marra C, Gamble JM, Abu AW. The effect of smartphone interventions on patients with chronic obstructive pulmonary disease exacerbations: a systematic review and meta-analysis. JMIR Mhealth Uhealth. 2016;4: e105.

57. Russell S, Ogunbayo OJ, Newham JJ, et al. Qualitative systematic review of barriers and facilitators to self-management of chronic obstructive pulmonary disease: views of patients and healthcare professionals. NPJ Prim Care Respir Med. 2018;28:2.

58. Lippiett KA, Richardson A, Myall M, Cummings A, May CR. Patients and informal caregivers' experiences of burden of treatment in lung cancer and chronic obstructive pulmonary disease (COPD): a systematic review and synthesis of qualitative research. BMJ Open. 2019;9:e020515.

59. Bergdahl IA, Torén K, Eriksson K, et al. Increased mortality in COPD among construction workers exposed to inorganic dust. Eur Respir J. 2004;23: 402-6. 
60. Humerfelt S, Gulsvik A, Skjærven R, et al. Decline in $\mathrm{FEV}_{1}$ and airflow limitation related to occupational exposures in men of an urban community. Eur Respir J. 1993;6:1095-103.

61. Diaz-Guzman E, Khosravi M, Mannino DM. Asthma, chronic obstructive pulmonary disease, and mortality in the U.S. population. COPD. 2011;8:400-7.

62. Balcan B, Akan S, Ugurlu AO, Handemir BO, Ceyhan $\mathrm{BB}$, Ozkaya $\mathrm{S}$. Effects of biomass smoke on pulmonary functions: a case control study. Int J Chronic Obstruct Pulm Dis. 2016;11:1615-22.

63. Burney P, Jithoo A, Kato B, et al. Chronic obstructive pulmonary disease mortality and prevalence: the associations with smoking and poverty-a BOLD analysis. Thorax. 2014;69:465-73.

64. Bodenheimer T, Wagner EH, Grumbach K. Improving primary care for patients with chronic illness. JAMA. 2002;288:1775-9.

65. Reynolds R, Dennis S, Hasan I, et al. A systematic review of chronic disease management interventions in primary care. BMC Fam Pract. 2018;19:11.

66. Battisti WP, Wager E, Baltzer L, et al. Good publication practice for communicating company-sponsored medical research: GPP3. Ann Intern Med. 2015;163:461-4. 